\title{
Diffusion Coefficient Analysis of Aluminum Electrolysis Spent Cathode as Anode Material For Lithium-ion Battery
}

\section{Wenlong Huang}

Xi'an University of Architecture and Technology

Jiaxin Peng

Xi'an University of Architecture and Technology

Jie Li

Xi'an University of Architecture and Technology

\section{Xueyang Hou}

Xi'an University of Architecture and Technology

\section{Xingliang Zhang}

Xi'an University of Architecture and Technology

\section{Zhao Fang ( $\nabla$ fangzhao@xauat.edu.cn )}

Xi'an University of Architecture and Technology

\section{Research Article}

Keywords: Lithium-ion Battery, Aluminum Electrolysis Spent Cathode, Diffusion Coefficient, GITT, EIS Posted Date: July 20th, 2021

DOl: https://doi.org/10.21203/rs.3.rs-720857/v1

License: (1) This work is licensed under a Creative Commons Attribution 4.0 International License. Read Full License

Version of Record: A version of this preprint was published at lonics on January 7th, 2022. See the published version at https://doi.org/10.1007/s11581-021-04398-y. 


\title{
Diffusion coefficient analysis of aluminum electrolysis spent cathode as anode material for lithium-ion battery
}

\author{
Wenlong Huang ${ }^{1}$, Jiaxin Peng ${ }^{1}$, Jie Li ${ }^{1}$, Xueyang Hou ${ }^{1}$, Xingliang Zhang ${ }^{1}$, Zhao Fang ${ }^{1,2, *}$ \\ 1. School of Metallurgical Engineering, Xi'an University of Architecture and Technology, Xi'an, \\ 710055, Shaanxi, China \\ 2. Shaanxi Province Metallurgical Engineering and Technology Research Centre, Xi'an, 710055, \\ China \\ * Corresponding authors. E-mail address: fangzhao@,xauat.edu.cn
}

\begin{abstract}
The aluminum electrolysis spent cathode (SC) was treated by hydrothermal method and used as anode material for lithium-ion battery. The purified SC material shows excellent electrochemical performance. In order to understand the diffusion behavior of $\mathrm{Li}^{+}$in the $\mathrm{SC}$ electrode, the diffusion coefficient of $\mathrm{Li}^{+}$in the $\mathrm{SC}$ electrode was systematically analyzed by galvanostatic intermittent titration technique (GITT), cyclic voltammetry (CV), and electrochemical impedance spectroscopy (EIS). The results show that the diffusion coefficient $\left(\mathrm{D}_{\mathrm{Li}^{+}}\right)$of $\mathrm{Li}^{+}$in $\mathrm{SC}$ electrode is calculated by $\mathrm{CV}$ is $2.2292 \times 10^{-11} \mathrm{~cm}^{2} \cdot \mathrm{s}^{-1}$, which is calculated by GITT and EIS ranges are $4.2286 \times 10^{-}$ ${ }^{13}-2.9667 \times 10^{-10} \mathrm{~cm}^{2} \cdot \mathrm{s}^{-1}, 4.05 \times 10^{-13}-3.87 \times 10^{-12} \mathrm{~cm}^{2} \cdot \mathrm{s}^{-1}$, respectively. SC electrode exhibits better $\mathrm{Li}^{+}$diffusion kinetics compared to commercial graphite (CG). In addition, the full cell of $\mathrm{LiNi}_{0.5} \mathrm{Co}_{0.2} \mathrm{Mn}_{0.3} \mathrm{O}_{2} / \mathrm{SC}$ also shows excellent cycle performance. After 80 cycles at $1 \mathrm{C} \quad\left(1 \mathrm{C}=172 \mathrm{~mA} \cdot \mathrm{g}^{-1}\right)$, the specific discharge capacity of $\mathrm{LiNi}_{0.5} \mathrm{Co}_{0.2} \mathrm{Mn}_{0.3} \mathrm{O}_{2} / \mathrm{SC}$ full-cell can reach $94.7 \mathrm{mAh} \cdot \mathrm{g}^{-1}$, and the capacity retention can reach $98.13 \%$. The fast lithium-ion diffusion rate and high discharge capacity provide a feasible direction for the high value utilization of aluminum electrolysis spent cathode.
\end{abstract} Keywords: Lithium-ion Battery, Aluminum Electrolysis Spent Cathode, Diffusion Coefficient, GITT, EIS

\section{Introduction}

In aluminum electrolysis industry of China, the main components of cathode are 
carbon materials. The constant penetration of electrolyte in the process of electrolysis makes the impurity content in the cathode graphite carbon block increase, which causes the cathode structure to be damaged and the electrolysis efficiency is reduced ${ }^{1}$. Therefore, it is necessary to replace the aluminum electrolysis cathode regularly. According to statistics, China produces about 500,000 tons of spent cathode carbon blocks from aluminum electrolysis every $y^{2}{ }^{2}$, and there is no effective treatment method. At present, most aluminum smelters use open stacking. Due to the spent cathode contains fluoride, cyanide and other toxic substances, which is a dangerous waste and has caused great security risks to the environment ${ }^{3}$. Therefore, how to deal with it innocently and make secondary high-value utilization has become a current research hotspot. Yuan w et al. analyzed the composition of aluminum electrolysis spent cathode in detail and found that the ratio of graphite to amorphous carbon was about 1.5:1, which indicated that it still had a high degree of graphitization ${ }^{4}$. Chen B et al. realized the closed recycling of the products by burning the spent cathode carbon block of aluminum electrolysis and adsorbed the fluoride in the combustion flue gas, which reduced the secondary pollution and reached the national allowable emission concentration $^{5}$. Wright $\mathrm{j}$ et al. used flotation chemical method to recover fluorine and carbon from spent cathode of aluminum electrolysis. The recovery rates of fluorine and carbon were up to $90.10 \%$ and $95.90 \%$ respectively, realizing zero discharge and harmless treatment of spentwater ${ }^{6}$. At present, most of the research on aluminum electrolysis spent cathode is harmless treatment, but how to make high-value utilization of them still needs further research.

Graphite is one of the main anode materials for Li-ion batteries by the reason of high specific discharge capacity, high compaction density, non-toxicity, stable cycling performance and better safety compared with lithium metal ${ }^{7}$. The spent cathode of aluminum electrolysis is graphite carbon block, which contains $60 \%-70 \%$ carbon $^{1}$. Therefore, it is an effective way to use it as anode of lithium-ion battery after impurity removal. Yang $\mathrm{K}$ et al. used the materials obtained by graphitization after impurity removal of aluminum electrolysis spent cathodes as anode materials for Li-ion battery ${ }^{8}$. The purified graphite exhibited excellent reversible discharge capacity and cycle 
retention. The deintercalation/intercalation mechanism of lithium ion in aluminum electrolysis spent cathodes was explained by graphite/graphene co-intercalation.

As a kind of secondary battery, lithium-ion battery mainly depends on the movement of lithium ions between the cathode and anode electrodes. During the charging process, $\mathrm{Li}^{+}$comes out from the cathode material and embeds into the anode material through the electrolyte. In contrast, $\mathrm{Li}^{+}$comes out from the anode material and embeds into the cathode material during the discharge process. Therefore, the cathode and anode materials of Li-ion battery are required to have excellent $\mathrm{Li}^{+}$ deintercalation/intercalation performance. The diffusion rate of $\mathrm{Li}^{+}$in the electrode direct influence on the charge and discharge rate of Li-ion battery. In the field of battery, the chemical diffusion coefficient is usually used to characterize the transfer characteristics of $\mathrm{Li}^{+}$, so it is very important to calculate the diffusion coefficient of $\mathrm{Li}^{+}$ in the electrode for understanding the kinetics of electrode materials. The methods commonly used to calculate the diffusion coefficient of $\mathrm{Li}^{+}$are galvanostatic intermittent titration technique (GITT), potentiostatic intermittent titration technique (PITT), electrochemical impedance spectroscopy (EIS) and cyclic voltammetry (CV) ${ }^{9-}$ 13. These methods have been widely used in the kinetics of electrode materials during charging and discharging of the battery.

In this paper, the aluminum electrolysis spent cathode carbon block was simply treated by hydrothermal method, and then it was used as electrode material to assemble the battery, and its cycle performance and rate performance were studied. The diffusion rate of $\mathrm{Li}^{+}$in $\mathrm{SC}$ electrode was studied by EIS, GITT and CV curves, and compared with $\mathrm{CG}$ electrode. It is found that the diffusion coefficient of $\mathrm{Li}^{+}$and specific discharge capacity in the SC electrode are higher than those of CG electrode. This may be due to the intercalation of $\mathrm{Al}^{3+}$ and $\mathrm{Na}^{+}$during the aluminum electrolysis process, which expands the graphite layer spacing, provides a wider diffusion path for the diffusion of $\mathrm{Li}^{+}$, and provides more sites for the intercalation of $\mathrm{Li}^{+}$. All these results confirm the feasibility of aluminum electrolysis spent cathodes as anode materials for Li-ion batteries. 


\section{Experimental}

\subsection{Impurity removal of aluminum electrolysis spent cathode}

After crushed the aluminum electrolysis spent cathode carbon block with a crusher, and taken $3 \mathrm{~g}$ put it into a $200 \mathrm{~mL}$ autoclave. Added $60 \mathrm{~mL} 4 \mathrm{M} \mathrm{HCl}$ into the autoclave and stir it thoroughly, and then reacted at $180^{\circ} \mathrm{C}$ for $12 \mathrm{~h}$. The product was filtered, dried it in an oven at $100^{\circ} \mathrm{C}$ for $24 \mathrm{~h}$. After ground, the spent cathode material after impurity removal can be obtained.

\subsection{Material characterization}

X-ray diffraction (XRD, D8 ADVANCE A25) was used to compare the lattice structure of spent cathode and commercial graphite under a scan speed of $5 \% \mathrm{~min}$ in the range of $2 \theta=10^{\circ}-80^{\circ}$. The graphitization was analyzed by Raman spectroscopy (HORIBA Scientific LabRAM HR Evolution). The morphology was analyzed by Field emission scanning electron microscopy (FE-SEM, Gemini SEM 300) for commercial graphite and spent cathode. The microstructure of the material was observed by Transmission electron microscope (TEM, FEI Tecnai G2 F20).

\subsection{Electrochemical measurements}

Preparation of graphite anode: Both SC and CG electrodes were prepared by mixing the active materials, acetylene black and polyvinylidene fluoride (PVDF, Canrd) were fully grinded at a mass ratio of $8: 1: 1$, and then N-methyl pyrrolidinone (NMP, AR, Canrd) solution was added dropwise to obtain the slurry. The slurry was evenly coated on the copper foil and then dried in the oven at $60{ }^{\circ} \mathrm{C}$ to remove NMP, and then it was cut into $14 \mathrm{~mm}$ pole pieces by the punching machine.

Preparation of $\mathrm{LiNi}_{0.5} \mathrm{Co}_{0.2} \mathrm{Mn}_{0.3} \mathrm{O}_{2}$ (NCM523) cathode: The commercial NCM523 material was mixed with acetylene black and PVDF at a mass ratio of 8:1:1. Added NMP solution to the above mixture, then it was coated on the aluminum foil after full grinding. Finally, dried and cut into pole pieces with a diameter of $14 \mathrm{~mm}$ for standby.

Assembly of half-cell: The battery was assembled in a glove box filled with argon 
by using the graphite electrode as the cathode electrode, $1 \mathrm{M} \mathrm{LiPF} 6$ in ethylene carbonate (EC): dimethyl carbonate (DMC): ethyl methyl carbonate (EMC) (1:1:1, v/v/v, DoDoChem) as the electrolyte, Celgard 2500 polypropylene diaphragm as the separator and lithium as the anode electrode.

Assembly of full-cell: NCM523 electrode, 1 M LiPF 6 in EC: DMC: EMC (1:1:1, v/v/v, DoDoChem), Celgard 2500 polypropylene diaphragm and graphite electrode were used as cathode electrode, electrolyte, separator and anode electrode, respectively. The battery was assembled in a glove box.

All the batteries were tested with LANHE-CT2001A (LANHE Product Series battery testing system) at $25^{\circ} \mathrm{C}$ and activated by a small current of $0.1 \mathrm{C}(1 \mathrm{C}=372$ $\mathrm{mA} \cdot \mathrm{g}^{-1}$ ) for two cycles before the test. The cycle performance of the battery was tested at $0.2,1.0$ and $2.0 \mathrm{C}$ (the full-cell test was calculated based on the theoretical specific capacity of cathode active material). The current intensity of $0.1,0.2,0.5,1.0,2.0,5.0$ and $10 \mathrm{C}$ was used for 5 cycles to test the rate performance, and then the chargedischarge test was continued with $0.1 \mathrm{C}$. The $\mathrm{CV}\left(0.005-2 \mathrm{~V}, 0.1,0.2,0.5,0.8,10 \mathrm{mV} \cdot \mathrm{s}^{-}\right.$ 1, respectively) curve and EIS $(1 \mathrm{MHz}-0.01 \mathrm{~Hz})$ were measured with Electrical Workstation (Parstat 4000A).

\section{Result and discussion}

Fig. 1a shows the XRD pattern of the aluminum electrolysis spent cathode material after impurity removal. It can be seen that the diffraction peak of the material is good agreement with that of Graphite-2h and no impurity peaks are found in the diffraction peak, which indicates that the impurities (such as $\mathrm{Al}_{2} \mathrm{O}_{3}, \mathrm{CaF}_{2}, \mathrm{Na}_{3} \mathrm{AlF}_{6}, \mathrm{Na}_{5} \mathrm{Al}_{3} \mathrm{~F}_{14}$, $\mathrm{NaF}$, etc. ${ }^{3,14}$ ) in the spent cathode carbon block of aluminum electrolysis are basically removed. The XRD results were processed by Jade software to obtain the lattice constants, the results are shown in Table 1. Compared with commercial graphite, the increase of $\mathrm{c}$ and $\mathrm{c} / \mathrm{a}$ value indicates that SC material has larger interlayer spacing, which provides a larger path for $\mathrm{Li}^{+}$diffusion between graphite layers. Through the calculation formula of graphitization degree $\left(\mathrm{P}=1-\left(\mathrm{d}_{002}-0.3354\right) /(0.344-0.3354)\right)^{15}$, it can be obtained the graphitization degree of SC material is $89.91 \%$. 
Table 1. Crystal lattice parameters of CG and SC material

\begin{tabular}{ccccccc}
\hline Sample & $\mathrm{a}(\AA)$ & $\mathrm{b}(\AA)$ & $\mathrm{c}(\AA)$ & $\mathrm{V}\left(\AA^{3}\right)$ & $\mathrm{c} / \mathrm{a}$ & Error $(\%)$ \\
\hline Commercial Graphite & 2.461 & 2.461 & 6.708 & 35.2 & 2.72572 & - \\
Spent Cathode & 2.46391 & 2.46391 & 6.72536 & 35.36 & 2.72955 & 0.3976 \\
\hline
\end{tabular}

In order to study the order of SC structure, the Raman spectra of SC were measured and compared with CG. The results are shown in Fig. 1b. The D peak near $1360 \mathrm{~cm}^{-1}$ represents the lattice defects of carbon atoms, and the $G$ peak near $1580 \mathrm{~cm}^{-1}$ corresponds to the in-plane stretching vibration of $\mathrm{sp} 2$ hybrid carbon atoms. The intensity ratio of $\mathrm{D}$ peak to $\mathrm{G}$ peak is commonly used to characterize the graphitization degree of carbon materials. It can be seen that CG sample has no diffraction peak near $1300 \mathrm{~cm}^{-1}$, which indicates that CG has no lattice defects and is an ordered pure graphite structure. However, SC has obvious diffraction peak at D, which may be due to the destruction of cathode structure during aluminum electrolysis, resulting in the defects of carbon lattice. Comparing the intensity ratio of $\mathrm{D}$ peak and $\mathrm{G}$ peak, $\mathrm{I}_{\mathrm{D}} / \mathrm{I}_{\mathrm{G}}=0.41$, which also shows that the material still has a high degree of graphitization, similar to XRD results.

(a)

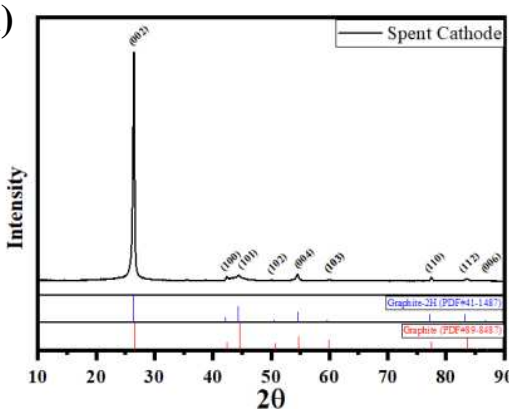

(b)

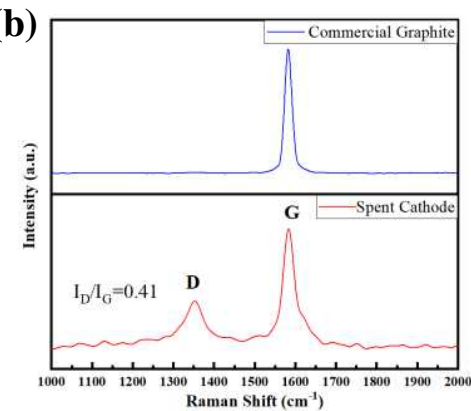

Fig. 1. (a) XRD patterns and (b) Raman diagram of SC and CG materials.

Fig. 2 shows the morphology of spent cathode material after purification. It can be seen from Fig. 2a that the SC material is a porous structure formed by agglomeration of small particles, which makes the material have a larger specific surface area, ensures that the electrolyte can fully contact with the electrode material, and shortens the diffusion path of $\mathrm{Li}^{+}$. At a larger magnification (as shown in Fig. 2b), it is observed that these small particles still have the flake-like structure of graphite with a size of 2-4 $\mu \mathrm{m}$. Fig. $2 \mathrm{c}$ and $2 \mathrm{~d}$ are the TEM and HRTEM of SC material, respectively. It can be seen that SC has a typical layered structure and obvious lattice fringes can be observed from 
Fig. 2d. Through line scanning of different regions (Fig. 2d1-d3), it can be observed that the lattice spacing of $\mathrm{d} 1, \mathrm{~d} 2$ and $\mathrm{d} 3$ regions are $0.341,0.353$ and $0.343 \mathrm{~nm}$ respectively, which correspond to the (002) plane of graphite ${ }^{16,17}$. The result shows that the interlayer spacing is larger than that of commercial graphite $(0.3354 \mathrm{~nm})$, which is consistent with the results of XRD.
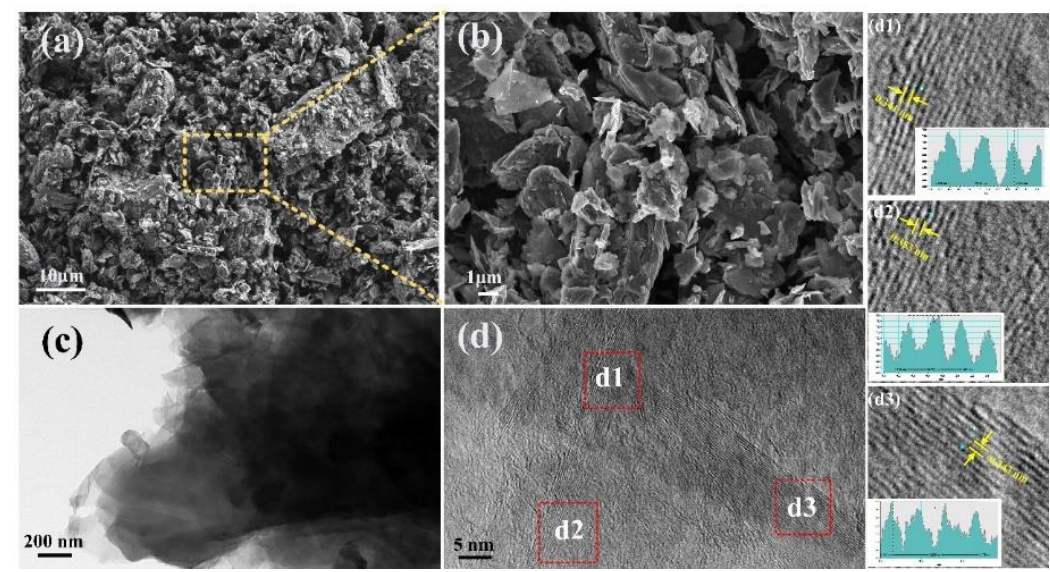

Fig. 2. (a, b) and (c, d) SEM and TEM of SC materials; (d1-d3) Corresponding lattice spacing scanned by the line scan.

Fig. 3 shows the cycle performance and rate performance of the half-cell assembled by SC and CG, respectively. The cycle performance of SC and CG electrodes at $0.2 \mathrm{C}\left(1 \mathrm{C}=372 \mathrm{~mA} \cdot \mathrm{g}^{-1}\right)$ is shown in Fig. 3a. The first two cycles were activated with $0.1 \mathrm{C}$, and the specific discharge capacities of SC and CG electrodes are as high as $482.5 \mathrm{mAh} \cdot \mathrm{g}^{-1}$ and $408.3 \mathrm{mAh} \cdot \mathrm{g}^{-1}$, respectively. When the current is increased to $0.2 \mathrm{C}$, the discharge specific capacities are $324.4 \mathrm{mAh} \cdot \mathrm{g}^{-1}$ and $262 \mathrm{mAh} \cdot \mathrm{g}^{-1}$, respectively. After 120 cycles, the capacities are $307.8 \mathrm{mAh} \cdot \mathrm{g}^{-1}$ and $257.1 \mathrm{mAh} \cdot \mathrm{g}^{-1}$, and the capacity retention rates are $94.88 \%$ and $98.13 \%$, respectively. Fig. $3 b$ and $3 c$ show the charge discharge curves of the first three cycles of SC and CG electrodes respectively. Although the degree of graphitization of SC is less than that of CG, the main lattice structure of SC still maintains the typical graphite structure. The discharge platform is kept below $0.5 \mathrm{~V}$ and has the same discharge curve as that of $\mathrm{CG}$ electrode. During the first cycle of activation, a voltage plateau appeared at $0.7 \mathrm{~V}$, which corresponding to the decomposition of electrolyte and the formation of SEI film ${ }^{18}$. The platform disappeared in the second circle and did not appear in the subsequent cycles. This is due to the SEI film was formed during the first circle, which inhibited the decomposition of the 
electrolyte $^{17}$. There are three discharge platforms in the range of 0.005-0.2 V, indicating that the deintercalation/intercalation behavior of $\mathrm{Li}^{+}$in the graphite electrode has obvious segmentation, which is consistent with that reported in the literature ${ }^{19,20}$. Fig. $3 \mathrm{~d}$ is the cycle performance graph of SC and CG electrodes at $2 \mathrm{C}$. It can be observed that SC electrode still has higher specific discharge capacity than CG electrode under high current. The coulomb efficiency of SC electrode is about $100 \%$, which indicates that the irreversible capacity of SC electrode is low during the cycle. Compared with CG electrode, the coulomb efficiency fluctuates significantly, so its irreversible capacity is higher, which leads to poor capacity retention. Fig. $3 \mathrm{e}$ and $3 \mathrm{f}$ are the rate performance of SC and CG electrodes and the first charge discharge curves under different discharge intensities respectively. At the initial low current of $0.1 \mathrm{C}$, there is little difference between the discharge specific capacities of SC and CG electrodes, but with the increase of current intensity, SC electrode shows higher discharge specific capacity. It can be seen from the charge discharge curve that the initial voltage of the charge discharge curve shifts with the increase of current intensity (as shown in the red dotted line box in Fig. 3f). This phenomenon is more intense, especially when the current intensity reaches $5.0 \mathrm{C}$ and $10 \mathrm{C}$, which indicates that there is a large polarization phenomenon on the electrode surface. Compared with CG electrode, SC electrode shows smaller polarization phenomenon and higher discharge capacity.

(a)

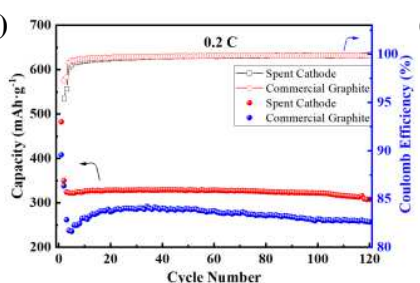

(d)

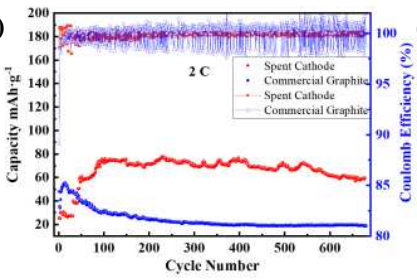

(b)
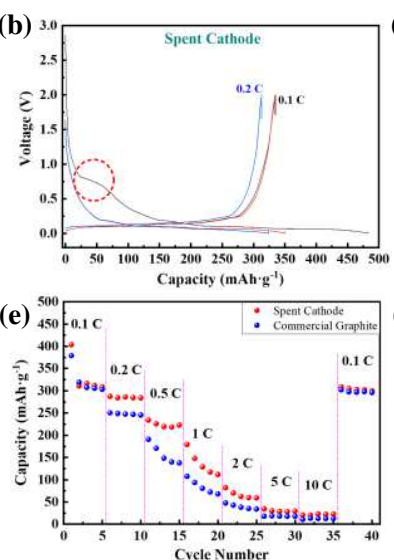
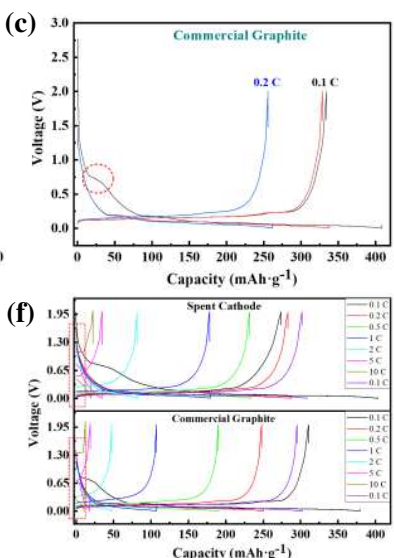

Fig. 3. (a, d) Cycle performance diagrams of the SC electrode and CG electrode at $0.2 \mathrm{C}$ and

$2 \mathrm{C}$, respectively; $(\mathrm{b}, \mathrm{c})$ First three cycles of the $\mathrm{SC}$ electrode and $\mathrm{CG}$ electrode at $0.2 \mathrm{C}$ current cycle Discharge curve; (e) Rate performance graph of SC electrode and CG electrode; (f) First cycle charge and discharge curve at different rates. 
Since the surface of the graphite electrode is prone to generate uneven and thick SEI film, it increases the time for $\mathrm{Li}^{+}$to diffuse. Moreover, graphite has high orientation, and $\mathrm{Li}^{+}$can only be inserted in the c-axis direction, so its high current discharge performance is not ideal. Compared with commercial graphite materials, SC materials have smaller lamellar size and larger interlayer spacing (c value), which can provide more insertion sites for $\mathrm{Li}^{+}$, thus improving the diffusion rate of $\mathrm{Li}^{+}$. In order to confirm the high diffusion rate of SC material, the diffusion coefficient of $\mathrm{Li}^{+}$in SC electrode is calculated by different methods and compared with CG material.

GITT is a new and effective method to calculate the diffusion coefficient of $\mathrm{Li}^{+}$by electrochemical titration. The calculation method is as follows ${ }^{21}$.

$$
\mathrm{D}_{\mathrm{GITT}}=\frac{4}{\pi}\left(\mathrm{I}_{0} \frac{\mathrm{V}_{\mathrm{m}}}{\mathrm{FS}}\right)^{2}\left(\frac{\mathrm{dE} / \mathrm{d} \chi}{\mathrm{dE} / \mathrm{dt} \mathrm{t}^{1 / 2}}\right)^{2}
$$

Where $D_{\text {GITT }}\left(\mathrm{cm}^{2} \cdot \mathrm{s}^{-1}\right)$ is the chemical diffusion coefficient, $\mathrm{I}_{0}(\mathrm{~A})$ is the applied current, $\mathrm{V}_{\mathrm{m}}\left(\mathrm{cm}^{3} \cdot \mathrm{mol}^{-1}\right)$ is the molar volume, $\mathrm{F}\left(96500 \mathrm{C} \cdot \mathrm{mol}^{-1}\right)$ is the Faraday constant, $\mathrm{S}\left(\mathrm{cm}^{2}\right)$ is the electrode/electrolyte contact area, $\mathrm{dE} / \mathrm{d} \chi$ is the slope of coulometric titration curve, $\mathrm{dE} / \mathrm{dt}^{1 / 2}$ is the relationship between potential and time. When the applied current $\left(\mathrm{I}_{0}\right)$ is very small and the discharge time $(\mathrm{t})$ is very short, the relationship of $\mathrm{dE} / \mathrm{dt}^{1 / 2}$ is linear, and the above formula can be simplified as $(2)^{22}$.

$$
\mathrm{D}_{\mathrm{GITT}}=\frac{4}{\pi \mathrm{\tau}}\left(\frac{\mathrm{n}_{\mathrm{B}} \mathrm{V}_{\mathrm{m}}}{\mathrm{s}}\right)^{2}\left(\frac{\Delta \mathrm{E}_{\mathrm{s}}}{\Delta \mathrm{E}_{\mathrm{t}}}\right)^{2}
$$

Where $\tau$ is the relaxation time, $\mathrm{n}_{\mathrm{B}}(\mathrm{mol})$ is the number of moles, $\Delta \mathrm{E}_{\mathrm{s}}(\mathrm{V})$ is the voltage change caused by the pulse, $\Delta \mathrm{E}_{\mathrm{t}}(\mathrm{V})$ is the voltage change of constant current charge and discharge. The GITT curves of SC and CG electrodes during discharge are shown in Fig. $4 a$ and $4 b$.

First, discharge with $0.1 \mathrm{C}$ current intensity for $10 \mathrm{~min}(\mathrm{t})$ and then stand for 50 $\min (\tau)$, repeat this process until the battery voltage drops to $0.005 \mathrm{~V}$. After substituting each unit $\Delta \mathrm{E}_{\mathrm{s}}$ and $\Delta \mathrm{E}_{\mathrm{t}}$, the diffusion coefficient of each unit can be calculated and the results are shown in Fig. $4 \mathrm{c}$ and $4 \mathrm{~d}$. The results show that the diffusion coefficient ranges of SC electrode and CG electrode are $4.2286 \times 10^{-13}-2.9667 \times 10^{-10} \mathrm{~cm}^{2} \cdot \mathrm{s}^{-1}$, $1.6346 \times 10^{-14}-2.8138 \times 10^{-10} \mathrm{~cm}^{2} \cdot \mathrm{s}^{-1}$, respectively. It can be seen that the diffusion coefficient of $\mathrm{Li}^{+}$in $\mathrm{SC}$ electrode is higher than that in $\mathrm{CG}$ electrode. This result can be 
attributed to the fact that ions with a larger radius (such as $\mathrm{Al}^{3+}, \mathrm{Na}^{+}$) are constantly deintercalation/intercalation in the cathode during aluminum electrolysis, which widens the graphite layer spacing and provides a wider diffusion path for $\mathrm{Li}^{+}$diffusion. The SC and $\mathrm{CG}$ electrodes both have high $\mathrm{Li}^{+}$diffusion coefficients at the beginning of the discharge. $\mathrm{As} \mathrm{Li}^{+}$is embedded in the graphite layer to generate $\mathrm{Li}_{\mathrm{x}} \mathrm{C}_{6}$, the diffusion coefficient gradually decreases and fluctuates greatly at the discharge platform. It can be seen that there are three valleys in the range of $0-0.2 \mathrm{~V}$, corresponding to the three discharge platforms on the discharge curve. In this stage, a large number of $\mathrm{Li}^{+}$floods into the graphite layer, leading to the phase transformation of graphite structure and reducing the diffusion rate $^{21}$.
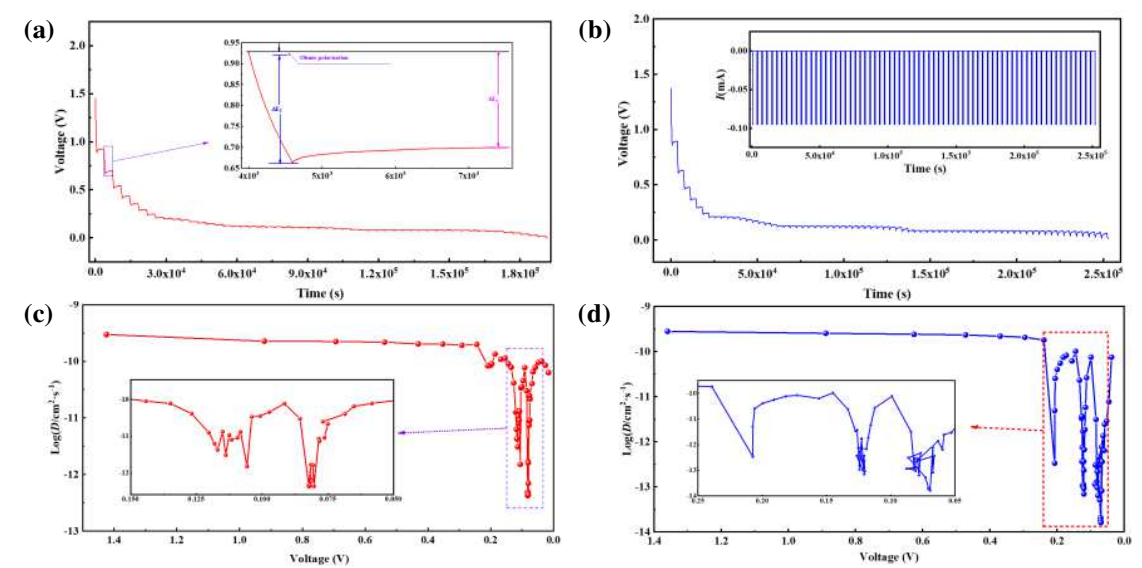

Fig. 4. (a, b) GITT curves of SC electrode and CG electrode at $\mathrm{O.1C}$; (c, d) $\mathrm{Li}^{+}$diffusion coefficients calculated by GITT for SC electrode and CG electrode.

The SC and CG electrodes were activated at $0.1 \mathrm{C}$ for two cycles and discharged at $0.2 \mathrm{C}$ current for every $30 \mathrm{~min}$. The EIS was tested after sufficient standing, and then continue discharged until the voltage was less than $0.005 \mathrm{~V}$. The impedance of SC and CG electrodes under different amount of lithium insertion are shown in Fig. 5a and 5b. It can be seen that the EIS impedance of the two samples is composed of SEI film impedance $\left(\mathrm{R}_{\mathrm{sf}}\right)$ corresponding to semicircle in high frequency region, charge transfer impedance $\left(\mathrm{R}_{\mathrm{ct}}\right)$ corresponding to semicircle in medium frequency region and Warburg impedance corresponding to oblique line in low frequency region ${ }^{23}$. The resistance values of each part are fitted by ZSimpWin software. The fitting circuit diagram is shown in Fig. 5e and the fitting results are shown in Table $2^{20}$. It can be seen from the results that $\mathrm{R}_{\mathrm{sf}}$ increased with the increase of discharge degree, which corresponds the 
gradual formation of SEI film. In addition, $\mathrm{SC}$ electrode has smaller $\mathrm{R}_{\mathrm{sf}}$ than $\mathrm{CG}$ electrode, which is due to the smaller size of SC particles, rough surface and larger specific surface area. Therefore, uniform SEI film is formed during the charging and discharging process to prevent the continuous decomposition of electrolyte and the occurrence of side reactions. The lower $\mathrm{R}_{\mathrm{ct}}$ is because $\mathrm{SC}$ materials can be better attached to copper collecting fluid, reduce the contact impedance between electrode materials and collecting fluid, which provide effective channels for charge transfer between graphite layer and collecting fluid. Therefore, SC electrode can achieve better discharge specific capacity and cycle stability ${ }^{24,25}$.

The Warburg impedance of EIS in low frequency region is related to the diffusion rate of lithium ion in SC and CG electrodes. The calculation formula of diffusion coefficient is as follows ${ }^{26,27}$.

$$
\mathrm{D}_{\mathrm{EIS}}=\frac{\mathrm{R}^{2} \mathrm{~T}^{2}}{2 \mathrm{~A}^{2} \mathrm{n}^{4} \mathrm{~F}^{4} \mathrm{C}^{2} \sigma^{2}}
$$

Where $D_{\text {EIS }}\left(\mathrm{cm}^{2} \cdot \mathrm{s}^{-1}\right)$ is the diffusion coefficient of lithium ion calculated by EIS, $\mathrm{R}\left(8.314 \mathrm{~J} \cdot \mathrm{mol}^{-1} \cdot \mathrm{K}^{-1}\right)$ is the ideal gas constant, $\mathrm{T}(\mathrm{K})$ is the absolute temperature, $\mathrm{A}\left(\mathrm{cm}^{2}\right)$ is the cross-sectional area of the electrode, $\mathrm{n}$ is the electron transfer number, F (96500 $\left.\mathrm{C} \cdot \mathrm{mol}^{-1}\right)$ is the Faraday constant, $\mathrm{C}\left(\mathrm{mol} \cdot \mathrm{cm}^{-3}\right)$ is the concentration of lithium ion in the electrode, $\sigma$ is Warburg factor, the calculation formula is as follows ${ }^{28}$.

$$
Z=\mathrm{R}_{\mathrm{s}}+\mathrm{R}_{\mathrm{ct}}+\sigma \omega^{-1 / 2}
$$

$\mathrm{Z}$ is proportional to the $-1 / 2$ power of the angular frequency $(\omega)$, and the slope $\sigma$ can be obtained by fitting. Fig. 5c shows the relationship diagram of $\omega^{-1 / 2}-Z$ when the CG electrode is discharged for $150 \mathrm{~min}$. The slope is 4.26447 , and the diffusion coefficient is $1.07 \times 10^{-12} \mathrm{~cm}^{2} \cdot \mathrm{s}^{-1}$ when substituted into the formula. Fig. $5 \mathrm{~d}$ is the diffusion coefficient of $\mathrm{Li}^{+}$calculated by EIS for SC and CG electrodes at different discharge times. It can be seen that the diffusion coefficient of $\mathrm{Li}^{+}$in $\mathrm{SC}$ and $\mathrm{CG}$ materials are $4.05 \times 10^{-13}-3.87 \times 10^{-12} \mathrm{~cm}^{2} \cdot \mathrm{s}^{-1}, 4.24 \times 10^{-13}-1.47 \times 10^{-12} \mathrm{~cm}^{2} \cdot \mathrm{s}^{-1}$, respectively, which are consistent with the results of GITT. 

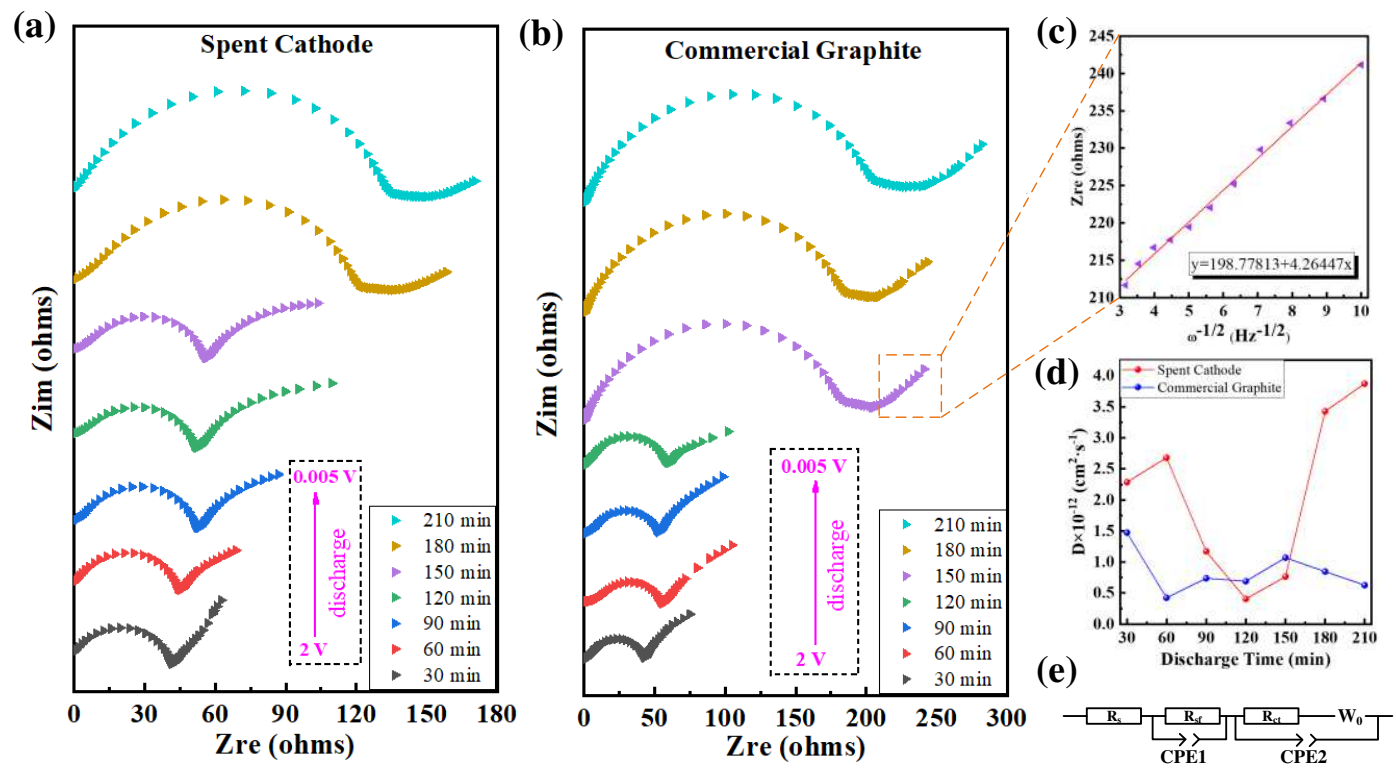

Fig. 5. (a, b) EIS impedance spectra of SC electrode and CG electrode under different discharge degrees at $0.2 \mathrm{C}$, respectively; (c) Linear fitting curve of $\omega^{-1 / 2}-\mathrm{Z}$ in low frequency region at 150 min for CG electrode; (d) Diffusion coefficient of $\mathrm{Li}^{+}$calculated by EIS; (e)

Fitting circuit diagram for EIS impedance.

Table 2. EIS impedance fitting results of SC and CG electrodes at different discharge degrees.

\begin{tabular}{ccccc}
\hline \multirow{2}{*}{ Time $(\min )$} & \multicolumn{2}{c}{ Spent Cathode } & \multicolumn{2}{c}{ Commercial Graphite } \\
\cline { 2 - 5 } & $\mathrm{R}_{\mathrm{sf}}(\mathrm{ohms})$ & $\mathrm{R}_{\mathrm{ct}}(\mathrm{ohms})$ & $\mathrm{R}_{\mathrm{sf}}(\mathrm{ohms})$ & $\mathrm{R}_{\mathrm{ct}}(\mathrm{ohms})$ \\
\hline 30 & 38.35 & 9.691 & 41.16 & 5.969 \\
60 & 42.78 & 13.93 & 53.20 & 1.802 \\
90 & 47.53 & 15.4 & 49.32 & 11.47 \\
120 & 46.07 & 23.39 & 61.24 & 35.7 \\
150 & 58.92 & 37.36 & 180.30 & 75.07 \\
180 & 124.30 & 15 & 187.20 & 3.613 \\
210 & 121.40 & 16.01 & 199.00 & 6.043 \\
\hline
\end{tabular}

Fig. $6 \mathrm{a}$ and $6 \mathrm{~b}$ show the $\mathrm{CV}$ curves of $\mathrm{SC}$ and $\mathrm{CG}$ samples in the voltage range of $0.005-2 \mathrm{~V}$ at a scan rate of $0.1 \mathrm{mV} / \mathrm{s}, 0.2 \mathrm{mV} / \mathrm{s}, 0.5 \mathrm{mV} / \mathrm{s}, 0.8 \mathrm{mV} / \mathrm{s}$ and $1.0 \mathrm{mV} / \mathrm{s}$, respectively. It can be seen that there is an obvious oxidation peak near $0.3 \mathrm{~V}$, which corresponds to the insertion of $\mathrm{Li}^{+}$in the graphite electrode. With the increase of scanning rate, the oxidation peak gradually shifts to the direction of high voltage, which corresponds to the discharge platform under different current intensities. The relationship between peak current $I_{p}$ and $v^{1 / 2}$, as shown in Fig. $6 \mathrm{c}$. It can be seen that the intercalation of lithium ions in graphite is obviously controlled by the diffusion rate, and the diffusion coefficient can be calculated by Randles Sevcik equation ${ }^{21,29}$. 


$$
\mathrm{I}_{\mathrm{p}}=0.4463 \mathrm{n}^{3 / 2} \mathrm{~F}^{3 / 2} \mathrm{CSR}^{-1 / 2} \mathrm{~T}^{-1 / 2} \mathrm{D}_{\mathrm{CV}}^{1 / 2} \mathrm{v}^{1 / 2}
$$

Where $I_{p}(A)$ is the peak current, $n$ is the charge transfer number, $F\left(96500 \mathrm{C} \cdot \mathrm{mol}^{-}\right.$ $\left.{ }^{1}\right)$ is the Faraday constant, $\mathrm{C}\left(\mathrm{mol} \cdot \mathrm{cm}^{-3}\right)$ is the concentration, $\mathrm{S}\left(\mathrm{cm}^{2}\right)$ is the electrode area, $\mathrm{R}\left(8.314 \mathrm{~J} \cdot \mathrm{mol}^{-1} \cdot \mathrm{K}^{-1}\right)$ is the gas constant, $\mathrm{T}(\mathrm{K})$ is the absolute temperature, and $\mathrm{D}_{\mathrm{CV}}\left(\mathrm{cm}^{2} \cdot \mathrm{s}^{-1}\right)$ is the chemical diffusion measured by CV, $v\left(\mathrm{~V} \cdot \mathrm{s}^{-1}\right)$ is the sweep speed. After linear fitting of $\mathrm{I}_{\mathrm{p}}-v^{1 / 2}$, the corresponding slopes of SC and CG are 0.05433 and 0.04203 , respectively. The diffusion coefficient of $\mathrm{Li}^{+}$in $\mathrm{SC}$ is $2.2292 \times 10^{-11} \mathrm{~cm}^{2} \cdot \mathrm{s}^{-1}$, while in CG is $1.3341 \times 10^{-11} \mathrm{~cm}^{2} \cdot \mathrm{s}^{-1}$. The results are consistent with the GITT results, which shows that all the values calculated by the three methods are in good agreement.

(a)

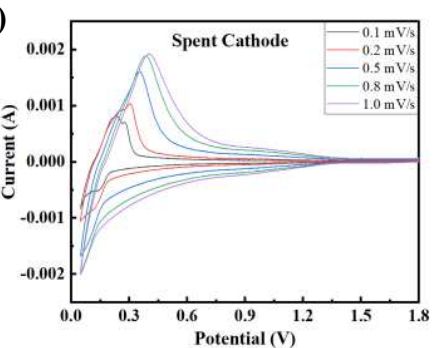

(b)

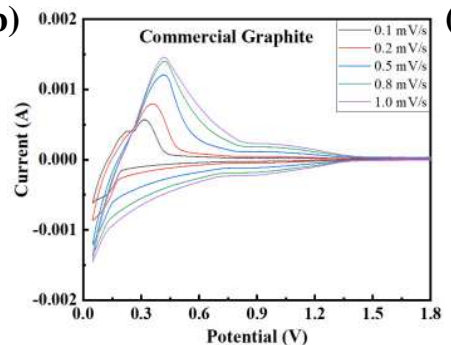

(c)

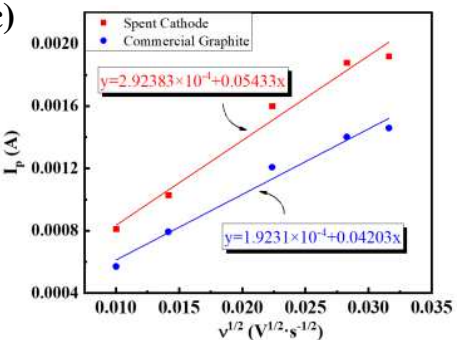

Fig. 6. (a, b) Cyclic voltammetry curves of SC electrode and CG electrode at different scanning rates; (c) linear fitting of $I_{p}-v^{1 / 2}$.

The above three calculation methods all show that the SC electrode has a high diffusion rate. In order to study the application of SC electrode in the full-cell, SC electrode and commercial NCM523 electrode were assembled into a full-cell. The cycle performance and rate performance are shown in Fig. 7. The initial discharge capacity is $151 \mathrm{mAh} \cdot \mathrm{g}^{-1}$ at $0.1 \mathrm{C}\left(1 \mathrm{C}=172 \mathrm{~mA} \cdot \mathrm{g}^{-1}\right)$ and the corresponding coulomb efficiency reaches $58.12 \%$ (commercial graphite is $114.5 \mathrm{mAh} \cdot \mathrm{g}^{-1}, 38.71 \%$ ). The first discharge capacity is $96.5 \mathrm{mAh} \cdot \mathrm{g}^{-1}$ at $1 \mathrm{C}$, and the capacity retention rate is $95.23 \%$ after 100 cycles. It can be seen from the rate performance that the capacity decreases rapidly at $0.1 \mathrm{C}$ current, which may be due to the formation of SEI film on the surface of graphite anode. With the gradual uniformity of SEI film, the capacity fading is suppressed. When the current intensity continues to increase, the capacity keeps stable under the same current intensity, which indicates that uniform and stable SEI film is formed at $0.1 \mathrm{C}$. When continuing to increase the current intensity, the SC electrode can provide specific capacity of $127.8,108.8,83.6,30.1 \mathrm{mAh} \cdot \mathrm{g}^{-1}$ at $0.2,0.5,1.0,2.0$, and $5 \mathrm{C}$, respectively. 
However, the discharge capacity of CG electrode is obviously low, and even the battery stops working at $5 \mathrm{C}$. The discharge capacity of SC electrode can reach $116.7 \mathrm{mAh} \cdot \mathrm{g}^{-1}$ with $0.1 \mathrm{C}$ after high current charge-discharge, while that of CG electrode is only 79.7 $\mathrm{mAh} \cdot \mathrm{g}^{-1}$. The cycle performance and rate performance indicate that SC electrode can provide enough insertion sites for $\mathrm{Li}^{+}$separated from cathode material, and maintain good structural stability during long-time cycling and high current intensity.

(a)

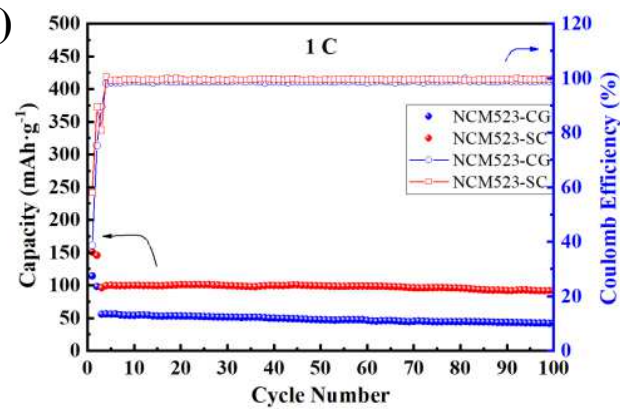

(b)

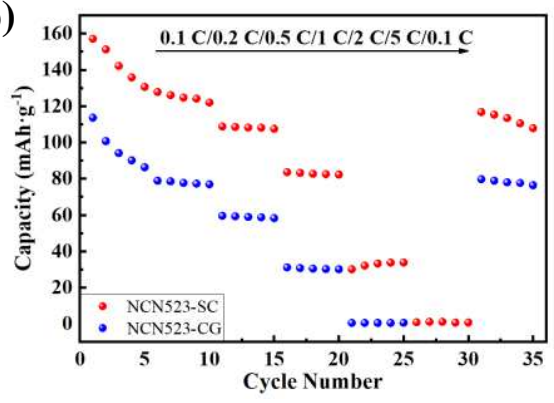

Fig. 7. Electrochemical performance of NCM523/graphite full-cell. (a) Cycle performance at $172 \mathrm{~mA} \cdot \mathrm{g}^{-1}$ and (b) Rate performance.

\section{Conclusion}

In this paper, the feasibility of aluminum electrolysis spent cathode as anode material for lithium-ion battery was studied. Through the structure, morphology and electrochemical performance, it can be seen that the purified SC material has the unique charge discharge characteristics of graphite, although the degree of graphitization is insufficient. SC material has rich pore structure and larger specific surface area, which can make the electrode material fully contact with electrolyte and reduce the generation of interface impedance. Meanwhile, the large interlayer spacing shortens the diffusion path of $\mathrm{Li}^{+}$and provides more active sites for lithium-ion intercalation, therefore proving a higher discharge capacity. The diffusion coefficient of lithium ion in aluminum electrolysis spent cathode was evaluated by GITT, EIS and cyclic voltammetry, and the results were compared with commercial graphite. The results calculated by different calculation methods are in good agreement. The calculation shows that the diffusion coefficient of $\mathrm{Li}^{+}$in spent cathode is in the range of $4.2286 \times 10^{-}$ ${ }^{13}-2.9667 \times 10^{-10} \mathrm{~cm}^{2} \cdot \mathrm{s}^{-1}$, which is higher than that of commercial graphite. Finally, SC material still shows a better discharge specific capacity and cycle stability when used 
in the full-cell. In this research, aluminum electrolysis spent cathode was treated by simple hydrothermal method and applied to lithium-ion batteries, and the good performance provides a high value utilization way for aluminum electrolysis spent cathode.

\section{Conflict of interest}

There is no conflict of interest for each contributing author.

\section{Acknowledgements}

This work was supported by the National Natural Science Foundation of China (52034011, 51974219), Natural Science Basic Research Plan in Shaanxi Province (2018JM5135). The authors would like to thank Shiyanjia Lab (www.shiyanjia.com) for the XRD and Raman analysis. 


\section{References}

[1] Li, R., Lu, T., Xie, M., Liu, F. Analysis on thermal behavior of fluorides and cyanides for heattreating spent cathode carbon blocks from aluminum smelters by TG/DSC-MS \& ECSA(R). Ecotoxicol Environ Saf. 189, 110015; 10.1016/j.ecoenv.2019.110015 (2020).

[2] Wang, Y., Peng, J., Di, Y. Separation and recycling of spent carbon cathode blocks in the aluminum industry by the vacuum distillation process. Jom. 70, 1877-1882; 10.1007/s11837-018-2858-4 (2018).

[3] Wang, Y., Chen, X. Discussion on recycling of spent cathode carbon blocks from aluminum smelters. Light Metals. 5, 31-35; (2020).

[4] Yuan, W., Jin, Z., Yang, Y. The process mineralogy research on aluminum electrolysis waste cathode. Yunnan Metallurgy. 41, 64-68; (2012).

[5] Chen, B., Yang, W., Yang, J., Wang, C., Jiang, J. Experimental study on treatment of aluminum reduction waste cathode carbon blocks by combustion method. Light Metals. 35-39; (2018).

[6] Wang, J., Liu, H., Luo, Y., Niu, Q., He, H., Shen, S. Study on harmless and resources recovery treatment technology of waste cathode carbon blocks from electrolytic aluminum. Procedia Environmental Sciences. 16, 769-777; 10.1016/j.proenv.2012.10.105 (2012).

[7] Ding, Z., Li, X., Wei, T., Yin, Z., Li, X. Improved compatibility of graphite anode for lithium ion battery using sulfuric esters. Electrochimica Acta. 196, 622-628; 10.1016/j.electacta.2016.02.205 (2016). [8] Yang, K., Zhao, Z., Xin, X., Tian, Z., Peng, K., Lai, Y. Graphitic carbon materials extracted from spent carbon cathode of aluminium reduction cell as anodes for lithium ion batteries: Converting the hazardous wastes into value-added materials. Journal of the Taiwan Institute of Chemical Engineers. 104, 201-209; 10.1016/j.jtice.2019.09.012 (2019).

[9] Liu, X., Wang, S., Wang, L., Wang, K., Wu, X., Zhou, P., Miao, Z., Zhou, J., Zhao, Y., Zhuo, S. Stabilizing the high-voltage cycle performance of $\mathrm{LiNi}_{0.8} \mathrm{Co}_{0.1} \mathrm{Mn}_{0.1} \mathrm{O}_{2}$ cathode material by $\mathrm{Mg}$ doping. Journal of Power Sources. 438, 227017; 10.1016/j.jpowsour.2019.227017 (2019).

[10] Maurin, G., Bousquet, C., Henn, F., Simon, B. Determination of the chemical diffusion coefficient of lithium in multiwall carbon nanotubes. Ionics. 5, 156-160; (1999).

[11] Liu, P., Xiao, L., Chen, Y., Chen, H. Highly enhanced electrochemical performances of $\mathrm{LiNi}_{0.815} \mathrm{Co}_{0.15} \mathrm{Al}_{0.035} \mathrm{O}_{2}$ by coating via conductively $\mathrm{LiTiO}_{2}$ for lithium-ion batteries. Ceramics International. 45, 18398-18405; 10.1016/j.ceramint.2019.06.055 (2019).

[12] Prosini, P., Lisi, M., Zane, D., Pasquali, M. Determination of the chemical diffusion coefficient of lithium in $\mathrm{LiFePO}_{4}$. Solid State Ionics. 148, 45-51; (2012).

[13] Tang, A., Wang, X., Xu, G., Zhou, Z., Nie, H. Determination of the chemical diffusion coefficient of lithium in $\mathrm{Li}_{3} \mathrm{~V}_{2}\left(\mathrm{PO}_{4}\right)_{3}$. Materials Letters. 63, 1439-1441; 10.1016/j.matlet.2009.03.035 (2009).

[14] Yang, K., Gong, P., Tian, Z., Lai, Y., Li, J. Recycling spent carbon cathode by a roasting method and its application in Li-ion batteries anodes. Journal of Cleaner Production. 261, 121090; 10.1016/j.jclepro.2020.121090 (2020).

[15] Zou, L., Huang, B., Huang, Y., Huang, Q., Wang, C. An investigation of heterogeneity of the degree of graphitization in carbon-carbon composites. Materials Chemistry and Physics. 82, 654-662; 10.1016/s0254-0584(03)00332-8 (2003).

[16] Liu, K., Yang, S., Luo, L., Pan, Q., Zhang, P., Huang, Y., Zheng, F., Wang, H., Li, Q. From spent graphite to recycle graphite anode for high-performance lithium ion batteries and sodium ion batteries. Electrochimica Acta. 356, 136856; 10.1016/j.electacta.2020.136856 (2020). 
[17] Zhu, T., Hu, Q., Yan, G., Wang, J., Wang, Z., Guo, H., Li, X., Peng, W. Manipulating the composition and structure of solid electrolyte interphase at graphite anode by adjusting the formation condition. Energy Technology. 7, 1900273; 10.1002/ente.201900273 (2019).

[18] Park, Y., Lee, S. Effects of particle size on the thermal stability of lithiated graphite anode. Electrochimica Acta. 54, 3339-3343; 10.1016/j.electacta.2008.12.030 (2009).

[19] Liao, X., Ding, Z., Yin, Z. Excellent performance of a modified graphite anode for lithium-ion battery application. Ionics. 5367-5373; 10.1007/s11581-020-03577-7 (2020).

[20] He, M., Zhou, H., Ding, G., Zhang, Z., Ye, X., Cai, D., Wu, M. Theoretical-limit exceeded capacity of the $\mathrm{N}_{2}+\mathrm{H}_{2}$ plasma modified graphite anode material. Carbon. 146, 194-199; 10.1016/j.carbon.2019.01.084 (2019).

[21] Tang, K., Yu, X., Sun, J., Li, H., Huang, X. Kinetic analysis on $\mathrm{LiFePO}_{4}$ thin films by CV, GITT, and EIS. Electrochimica Acta. 56, 4869-4875; 10.1016/j.electacta.2011.02.119 (2011).

[22] Wu, L., Tang, X., Chen, X., Rong, Z., Dang, W., Wang, Y., Li, X., Huang, L., Zhang, Y. Improvement of electrochemical reversibility of the Ni-rich cathode material by gallium doping. Journal of Power Sources. 445, 227337; 10.1016/j.jpowsour.2019.227337 (2020).

[23] Yu, J., Huang, W., Meng, B., Wang, L., Zhao, J., Li, L., Du, X., Fang, Z. Enhanced rate performance and high current cycle stability of $\mathrm{LiNi}_{0.8} \mathrm{Co}_{0.1} \mathrm{Mn}_{0.1} \mathrm{O}_{2}$ by sodium doping. Materials Express. 9, 895-905; 10.1166/mex.2019.1581 (2019).

[24] Fan, X., Ni, K., Han, J., Wang, S., Gou, L., Li, D. Cathodic electrodeposition of porous $\mathrm{MnO}_{2}$ film as binder-free cathode for high performance rechargeable Zinc-ion battery. Functional Materials Letters. 12, 1950073; 10.1142/s1793604719500735 (2019).

[25] Kim, H., Choi, W. Graphene modified copper current collector for enhanced electrochemical performance of Li-ion battery. Scripta Materialia. 146, 100-104; 10.1016/j.scriptamat.2017.11.030 (2018)

[26] Musuvadhi Babulal, L., Yang, C., Wu, S., Chien, W., Jose, R., Jessie Lue, S. Enhanced performance of a Ni-rich $\mathrm{LiNi}_{0.8} \mathrm{Co}_{0.1} \mathrm{Mn}_{0.1} \mathrm{O}_{2}$ cathode material formed through taylor flow synthesis and surface modification with $\mathrm{Li}_{2} \mathrm{MoO}_{4}$. Chemical Engineering Journal. 127150; 10.1016/j.cej.2020.127150 (2020).

[27] Nguyen, V., Jin, E., Gu, H. Synthesis and electrochemical properties of $\mathrm{LiFePO}_{4}$-graphite nanofiber composites as cathode materials for lithium ion batteries. Journal of Power Sources. 244, 586591; 10.1016/j.jpowsour.2013.01.073 (2013).

[28] Qu, X., Yu, Z., Ruan, D., Dou, A., Su, M., Zhou, Y., Liu, Y., Chu, D. Enhanced electrochemical performance of Ni-rich cathode materials with $\mathrm{Li}_{1.3} \mathrm{Al}_{0.3} \mathrm{Ti}_{1.7}\left(\mathrm{PO}_{4}\right)_{3}$ coating. ACS Sustainable Chemistry \& Engineering. 8, 5819-5830; 10.1021/acssuschemeng.9b05539 (2020).

[29] Peng, J., Zhong, K., Huang, W., Hou, X., Gao, H., Fang, Z., Li, L. Regulation of an inner helmholtz plane by hierarchical porous biomass activated carbon for stable cathode electrolyte interphase films. Vacuum. 191, 110331; 10.1016/j.vacuum.2021.110331 (2021). 